\title{
Peha-haft bandage as a new dressing for pediatric hypospadias repair
}

\author{
A. N. Gangopadhyay, S. Sharma \\ Department of Paediatric Surgery, University Hospital, Institute of Medical Sciences, Banaras Hindu University, \\ Varanasi - U.P., India
}

Address for correspondence: A.N. Gangopadhyay, Professor \& Head, Department of Pediatric Surgery, Institute of Medical Sciences, Banaras Hindu University, Varanasi - 221 005, E-mail: gangulybhu@rediffmail.com

\section{ABSTRACT}

Hypospadias Repair has varied alternatives in every step including dressing.

Objective: To compare Peha-Haft cohesive dressing with compressed gauze penile wrap dressing in hypospadias repair.

Patients and methods: Peha-Haft cohesive dressing was prospectively used in 60 subjects (Group A) over a period of three and a half years from Jan.2001 to July 2004 and compared with 60 subjects of compressed gauze dressing with micropore adhesive (Group B). Primary outcome measures were ease of application, cost, comfort with dressing, dressing related early complications, pain during dressing removal assessed by FLACC score and time taken during removal.

Results: Time taken during dressing removal was $30+11$ seconds in Group A and $180+26$ seconds in Group B. FLACC score was $3+2$ in Group A and $7+3$ in Group B. No sedation was required in the Group A while it was required in 26 cases in Group B.

Conclusion: Peha-Haft dressing was superior in terms of the ease of application, cost, comfort with dressing, dressing related early complications, time consumed and pain during dressing removal.

\section{KEY WORDS}

Hypospadias dressing, Peha-Haft bandage

\section{INTRODUCTION}

emoval of hypospadias repair dressing is painful for the apprehensive pediatric patient and a time consuming one for the surgeon. A novel dressing material was found useful in solving both these issues.

\section{PATIENTS AND METHODS}

In Group A, sixty subjects of hypospadias repair were dressed with Peha-Haft dressing [Figure 1]. Sofratulle was wrapped around the penile shaft followed by gauze and three turns of peha-haft double folded along its width. No additional adhesive was applied to penile shaft. In sixty subjects of Group B, sofratulle followed by 4-7 turns of gauze and 3-4 turns of micropore adhesive was applied. Distribution of cases was on random basis. Mean age of patients was $5.26 \pm 2.24$ years (Range: $3-12$ years) in group $A$ and $4.92 \pm 2.40$ (Range 2.5-10 years) in group B. In group A, 28; 15; 13 and 4 patients and in group B, 32; 12;10 and 6 had distal; mid; proximal penile and scrotal hypospadias, respectively. Type of urethroplasty was Mathieu's, Snod Grass, Duckett's, Asopa's, Theirsch Duplay, Free preputial graft and combined scrotal flap in 9, 4, 10, 15, 4, 16 and 2 in group A and 7, 2, 14, 19, 2, 12 and 4 in group B. First dressing was changed on fifth post-operative day. Time 


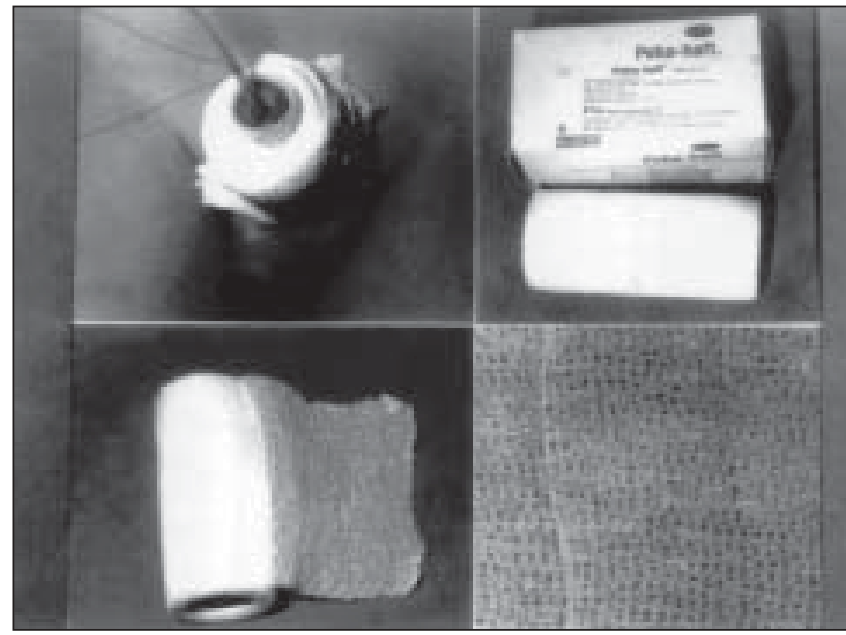

Figure 1: Peha Haft Bandage used for Pediatric Hypospadiac dressing

taken for dressing removal, pain assessed by FLACC scoring and requirement of sedation was noted. [Table 1]. ${ }^{1}$ FLACC is a behavioral pain scale used to assess the post operative pain in children. FLACC stands for Face, Legs, Activity, Cry and Consolability. Each category is scored from 0-2. The total score varies from $0-10$. The scores are interpreted as $0=$ relaxed and comfortable, $1-3=$ mild discomfort, $4-6=$ moderate pain and $7-10=$ severe pain.

Second dressing on tenth post-operative day was not included in the study as it did not involve removal of a haemostatic compression dressing.

\section{RESULTS}

Both groups were comparable in terms of age, type of hypospadias and repair done. Peha-Haft dressing was easier to apply and could be applied with gloves. It could be reapplied to adjust tightness. No patient complained of discomfort with dressing in group A while 12 patients complained of pain and 6 of itching in group B. Four patients in group B had significant preputial odema requiring slitting open of dressing. There was no wound infection or allergic reaction in group A. Infection was noted in 3 patients in group B. Scab formation occurred in 2 patients in group A and 5 in group $B$. The dressing came out spontaneously in 4 patients in group $B$. Time taken for dressing removal was $30 \pm 11$ seconds in group $A$ and $180 \pm 26$ seconds in group B. FLACC pain score during removal was $3 \pm 2$ in Group A and $7 \pm 3$ in Group B. No sedation was required for group A though it was required for 26 cases (43\%) in group B.

\section{DISCUSSION}

Dressing following hypospadias repair is a controversial issue with a multitude of techniques described. While some concluded that no dressing is required, others have used innovative methods. ${ }^{2}$ The authors believe that dressing is essential to control post-operative oedema, prevent haematoma formation that predisposes to infection and as a barrier from surroundings. Use of an additional barrier film has been reported to save time. ${ }^{3}$ Novel methods used and found suitable include polyurethrane bio occlusive foil, Cavi care, SANAV, glove-finger, Fibrin seal (Tisseal), Melolin and adhesive membrane dressings. ${ }^{410}$ Silicon foam dressing was found effective in restricting edema, haematoma formation and stabilization with easy removal. ${ }^{11}$

Peha-Haft is a cohesive elastic conforming bandage with extra strong adhesive effect due to its crepe texture and special latex coating. It adheres to itself, but not to skin, hair or clothes. It may be stretched $100 \%$ or more, no reverse turns are necessary. It is highly porous due to open-weave structure and light impregnation allowing aeration of the wound and preventing infection. It is very absorbent and gentle to skin due to high percentage of natural fibers and neutral latex coating. It's a little stiff so keeps the penile shaft straight. It can be easily peeled off from itself during

Table 1: FLACC Behavioral Pain Scale

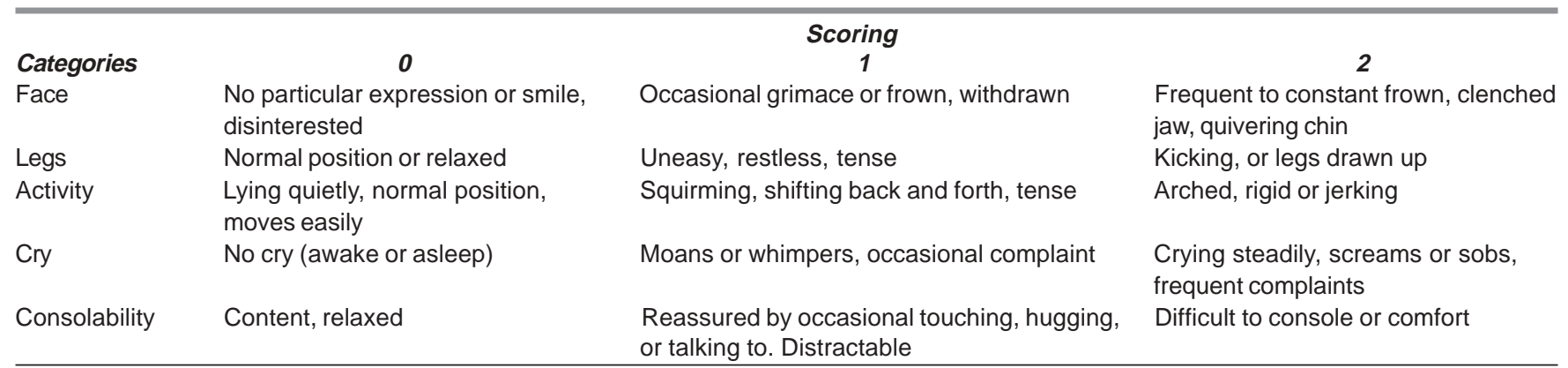

Each category is scored from $0-2$. Total score $0-10$, Total FLACC score $0=$ relaxed and comfortable, $1-3=$ mild discomfort, $4-6=$ moderate pain and 7- $10=$ severe pain. 
removal thus saving time. Peri-catheter leak can be easily identified due to its soakage properties and white colour. It serves as an ideal compressive bandage as no case developed any swelling or haematoma and is cost effective as one pack consisting of 4 meters can be used in 16-20 cases.

At our University hospital, we are now routinely using PehaHaft bandage in all cases of pediatric hypospadias repair and recommend its generous use as an ideal dressing material with all desirable qualities.

\section{Footnote}

Peha Haft is a registered trademark of Elder pharmaceuticals private limited (Corporate office - Mumbai,). We have not received any aid from this company for this study.

\section{REFERENCES}

1. Merkel SI, Voepel-Lewis T, Shayevitz JR, Malviya S. The FLACC: A behavioral scale for scoring postoperative pain in young children. Pediatr Nurs 1997;23:293-7.
2. Van Savage JG, Palanca LG, Slaughenhoupt BL. A prospective randomized trial of dressing versus no dressings for hypospadias repair. J Urol 2000;164:981-3.

3. Sanders $\mathrm{C}$. Comparison of dressing removal following hypospadias repair.Br J Nurs 2003;12:S21-8.

4. Skrobisz P, Mikolajczyk A, Fryc D,Bilski P. Use of polyurethane Biolusive foil from Johnson and Johnson, as a dressing after surgery for hypospadias in children. Wiad Lek 1998;51:120-3.

5. Davalbhakta A, Summerlad BC. Cavi-Care dressing for hypospadias repair. Br J Plast Surg 1999;52:325-6.

6. Searles JM, Mackinnon AE. The "SANAV "of hypospadias dressing. BJU Int 2001;87:531-3.

7. Singh RB, Khatri HL, Sethi R. Glove-finger dressing in pediatric hypospadias. Pediatr Surg Int. 2002;18:218-9.

8. Ohsumi N. Postoperative compressive penile dressing using fibrin seal (Tisseal) and tulle gauze for hypospadias repair. Plast Reconstr Surg. 1998;101:1737-8.

9. Vordermerk JS. Adhesive membrane: a new dressing for hypospadias. Urology 1982;20:86.

10. Schumacher S, Fisch M,Schurig E, Hohenfellner R. Properties and acceptance of Melolin wound dressing in postoperative management of male urethral reconstruction. Urologe A.1996;35:14-7.

11. Gaylis FD, Zaontz MR, Dalton D, et al. Silicone foam dressing for penis after reconstructive pediatric surgery. Urology.1989; 33: 2969. 